\title{
SEAWATER RADIOCARBON EVOLUTION IN THE GULF OF ALASKA: 2002 OBSERVATIONS
}

\author{
Thomas P Guilderson ${ }^{1,2} \bullet$ E Brendan Roark ${ }^{3,4} \bullet$ Paul D Quay $^{5} \cdot$ Sarah R Flood Page $e^{6,7} \bullet$ \\ Christopher Moy ${ }^{8}$
}

\begin{abstract}
Oceanic uptake and transport of bomb radiocarbon as ${ }^{14} \mathrm{CO}_{2}$ created by atmospheric nuclear weapons testing in the 1950s and 1960s has been a useful diagnostic for determining the carbon transfer between the ocean and atmosphere. In addition, the distribution of ${ }^{14} \mathrm{C}$ in the ocean can be used as a tracer of oceanic circulation. Results obtained on samples collected in the Gulf of Alaska in the summer of 2002 provide a direct comparison with results in the 1970s during GEOSECS and in the early 1990s during WOCE. The open gyre values are 20-40\%o lower than those documented in 1991 and 1993 (WOCE), although the general trends as a function of latitude are reproduced. Surface values are still significantly higher than pre-bomb levels ( -105\% or lower). In the central gyre, we observe $\Delta^{14} \mathrm{C}$ values that are lower in comparison to GEOSECS (stn 218) and WOCE P16/P17 to a density of $\sim 26.8 \sigma_{\mathrm{t}}$. This observation is consistent with the overall decrease in surface $\Delta^{14} \mathrm{C}$ values and reflects the erosion of the bomb- ${ }^{14} \mathrm{C}$ transient. We propose that erosion of the bomb- ${ }^{14} \mathrm{C}$ transient is accomplished by entrainment of low- ${ }^{14} \mathrm{C}$ water via vertical exchange within the Gulf of Alaska and replenishment of surface and subthermocline waters with waters derived from the far northwest Pacific.
\end{abstract}

\section{INTRODUCTION}

Due to the long radioactive half-life, the oceanic distribution of natural radiocarbon $\left({ }^{14} \mathrm{C}\right.$ expressed as $\Delta^{14} \mathrm{C}$; Stuiver and Polach 1977) reflects centennial- to millennial-scale circulation. Atmospheric nuclear testing in the 1950 s and early 1960 s resulted in an excess of ${ }^{14} \mathrm{C}$, which augmented the natural ${ }^{14} \mathrm{C}$ gradient between surface and subsurface waters. This contrast makes the distribution of ${ }^{14} \mathrm{C}$ in the surface ocean particularly sensitive to vertical mixing and lateral exchange. Oceanic uptake and transport of bomb ${ }^{14} \mathrm{C}$ as ${ }^{14} \mathrm{CO}_{2}$ has been a useful diagnostic for determining the carbon transfer between the ocean and atmosphere and as a transient tracer of ocean circulation. The present-day distribution of bomb ${ }^{14} \mathrm{C}$ in the ocean reflects the integration of variable circulation and air-sea $\left({ }^{14} \mathrm{CO}_{2}\right)$ exchange over the last $\sim 45 \mathrm{yr}$.

We present $\Delta^{14} \mathrm{C}$ data of the total dissolved inorganic carbon $\left(\Sigma \mathrm{CO}_{2}\right)$ determined on surface water and samples from 2 hydrocasts collected in June/July of 2002 in the Gulf of Alaska. These results are compared to similar $\Delta^{14} \mathrm{C}$ data obtained during WOCE sections P16n (1991) and P17n (1993), opportunistic cruises in the 1980s, and GEOSECS station 218 in 1973.

\section{NORTH PACIFIC CIRCULATION}

In general, the shallow sub-subsurface circulation of the subpolar North Pacific follows the winddriven circulation, creating a large subpolar cyclonic gyre north of $40^{\circ}$ (Figure 1) (cf. Sverdrup et al. 1942; Reid and Arthur 1975). The southern edge of the subarctic gyre is delineated by the eastwardflowing North Pacific Current, which is sourced in the far west from the Kuroshio Current. The position of the southern boundary varies seasonally and to a large extent tracks the zero curl of the

\footnotetext{
${ }^{1}$ Center for Accelerator Mass Spectrometry, LLNL, Livermore, California 94551, USA. Corresponding author. Email: tguilderson@1lnl.gov.

${ }^{2}$ Department of Ocean Sciences, University of California-Santa Cruz, Santa Cruz, California 94056, USA.

${ }^{3}$ Department of Geography, University of California-Berkeley, Berkeley, California 94720, USA.

${ }^{4}$ Now at Department of Geological and Environmental Sciences, Stanford University, Stanford, California 94305, USA.

${ }^{5}$ School of Oceanography, University of Washington, Seattle, Washington 98195, USA.

${ }^{6}$ Department of Biological Sciences, University of California-Santa Cruz, Santa Cruz, California 94056, USA.

${ }^{7}$ Now at Department of Earth and Planetary Sciences, Harvard University, Cambridge, Massachusetts 02138, USA.

${ }^{8}$ Department of Geological and Environmental Sciences, Stanford University, Stanford, California 94305, USA.
} 
wind-stress. The Gulf of Alaska contains the third and easternmost of the subarctic cyclonic gyres imbedded in the overall cyclonic gyre of the subarctic. The Alaskan Gyre is bounded to the east by the Alaskan Current, which east of Kodiak Island converges with the strong westward-flowing Alaskan Stream. The western boundary is nominally at $180^{\circ}$ where the Aleutian Islands dip furthest south and force the Alaskan Stream south, essentially closing the small gyre. In the Gulf of Alaska, and the whole of the subpolar North Pacific, low surface water salinity maintains a large density contrast, which in general suppresses deep convection. Climatological winter mixed-layer depths are on the order of 100-200 m (Monterey and Levitus 1997). West to east across the subpolar North Pacific, isopycnals trend downward (Figure 1). Coastal downwelling and deepening of isopycnals to the south of the Alaskan Gyre dominate the north-south trend (Figure 1). Bowing up of isopycnals in the center of the gyre along the meridional profile is consistent with wind-driven Ekman divergence and the large-scale North Pacific wind field.
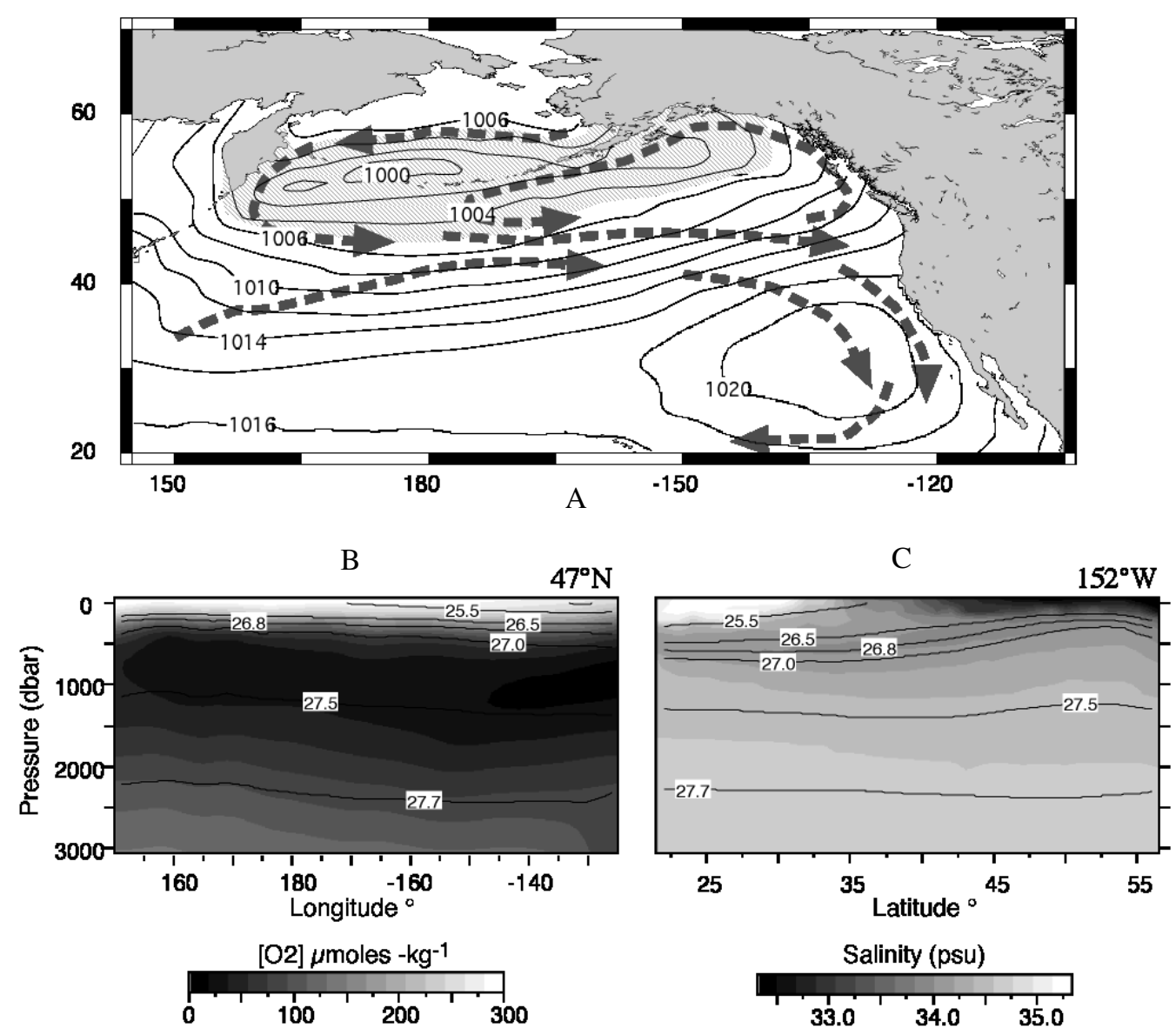

Figure 1 a) Winter sea level pressure (mbar) and surface currents; stippled area is Aleutian Low; b) Oxygen profile along $47^{\circ} \mathrm{N}$; contours are lines of potential density $\left(\sigma_{\mathrm{t}}\right)$ in $\mathrm{kg} / \mathrm{m}^{3}$. Note that the isopycnals slope down to the east; c) Salinity profile along $152^{\circ} \mathrm{W}$, with lines of potential density overlain. Data presented in $b$ and $c$ along $47^{\circ}$ and $152^{\circ}$ come from the R/V Thomas Thompson WOCE cruises.

There are relatively few easily characterizable subsurface water masses in the North Pacific. A major subthermocline water type is North Pacific Intermediate Water (NPIW), which is character- 
ized by low salinity ( 33.9 psu) and high oxygen content (e.g. Talley 1991; Talley et al. 1991; Tsunogai et al. 1995). Utilizing salinity and oxygen to define NPIW places the core of this water mass at a potential density $\left(\sigma_{t}\right)$ of $26.8 \mathrm{~kg} / \mathrm{m}^{3}$. NPIW is one of the major interior water masses of the North Pacific, and its fundamental characteristics can be traced to $\sim 20^{\circ} \mathrm{N}$ and along Baja to near the Equator. Waters of this density (in a climatological sense) do not outcrop in the open subpolar North Pacific, and it has been determined that the source of much of this water is from the Sea of Okhotsk (Talley 1991; Talley et al. 1991). The northern extent of NPIW is delimited by the subarctic front, except in the east where a tongue of low-salinity water at the appropriate density is found around the eastern side of the Gulf of Alaska (Talley 1993).

Transient tracers such as chlorofluorocarbon and "bomb"-derived tritium and ${ }^{14} \mathrm{C}$ data indicate that NPIW is in general a few decades old (e.g. Watanabe et al. 1994; Warner et al. 1996; Tsunogai et al. 1995; Van Scoy et al. 1991a) and that the circulation follows that of the surface waters, albeit offset slightly to the east and south. The tracer data indicate that direct air-sea exchange in the open North Pacific is limited, with most of NPIW being formed in the Sea of Okhotsk. However, in their analysis of transient tracer data Van Scoy et al. (1991b) inferred that there does appear to be wintertime ventilation in the Gulf of Alaska with sufficient vigor as to mix into NPIW. Subsequent analysis of WOCE P17 chlorofluorocarbon and hydrographic data collected in 1993 (Aydin et al. 1998) imply modification of NPIW and subsurface waters within the Gulf of Alaska and the Alaskan Gyre in particular.

\section{METHODS}

Water samples were collected in June and July of 2002 during the Gulf of Alaska Seamount Expedition (GoASEx-2002) on the R/V Atlantis (ATL 7/15 and ATL 7/16: Figure 2). The southern boundary of the subpolar gyre is approximately demarked by the zero-line of the curl of the windstress. To estimate the southern end of the gyre, we calculated the zero-line of the curl of the windstress using a simple bulk formula approximation of the $\mathrm{u} / \mathrm{v}$ stress and the average May-June 2002 surface $u$ and $v$ wind velocities provided by the NCEP reanalysis (cdc.noaa.gov). In this case, we calculated pseudo-stress; for the $u$ vector this is given by $\tau_{u}=\rho_{a} \times C_{d} \times \operatorname{abs}(U) \times U$ where $\rho_{a}$ is the density of air, $C_{d}$ is a unit-less drag coefficient $\sim 1.4 \times 10^{-3}$, and $U$ is the $u$ component of the wind velocity. The southernmost stations are likely to have been either outside the gyre or at the gyre boundary in the North Pacific Current (Figure 2). This would be comparable with Western Subpolar water and the transition zone described in Aydin et al. (1998).

Underway samples were taken from the vessel's continuous-flow clean seawater line after purging the line for at least $5 \mathrm{~min}$ before collection. Two sets of hydrocast samples were collected using a niskin-CTD array at Patton (ATL 7-15 ctd1: $53.93^{\circ} \mathrm{N}, 148.43^{\circ} \mathrm{W}$ ) and Warwick (ATL7-16 ctd2: $47.95^{\circ} \mathrm{N}, 132.92^{\circ} \mathrm{W}$ ) seamounts. Half-liter glass bottles were filled from the bottom and allowed to flush for twice their volume prior to poisoning with mercuric chloride and storage. Following standard protocols (e.g. Dickson and Goyet 1994), total dissolved inorganic carbon was quantitatively stripped via acidification and purging with nitrogen at the School of Oceanography, University of Washington (UW). Aliquots of cryogenically purified $\mathrm{CO}_{2}$ were analyzed for $\delta^{13} \mathrm{C}$ (\%o VPDB) at $\mathrm{UW}$, and the remaining $\mathrm{CO}_{2}$ transferred to the Center for Accelerator Mass Spectrometry (CAMS) in glass ampules.

$\mathrm{CO}_{2}$ was reduced to elemental carbon (graphite) in the presence of iron catalyst and a stoichiometric excess of hydrogen similar to the method described by Vogel et al. (1987). Graphite targets were measured at CAMS. Raw data $\left({ }^{14} \mathrm{C} /{ }^{13} \mathrm{C}\right.$ ratios) are normalized to the average of 6 bracketing aliquots 


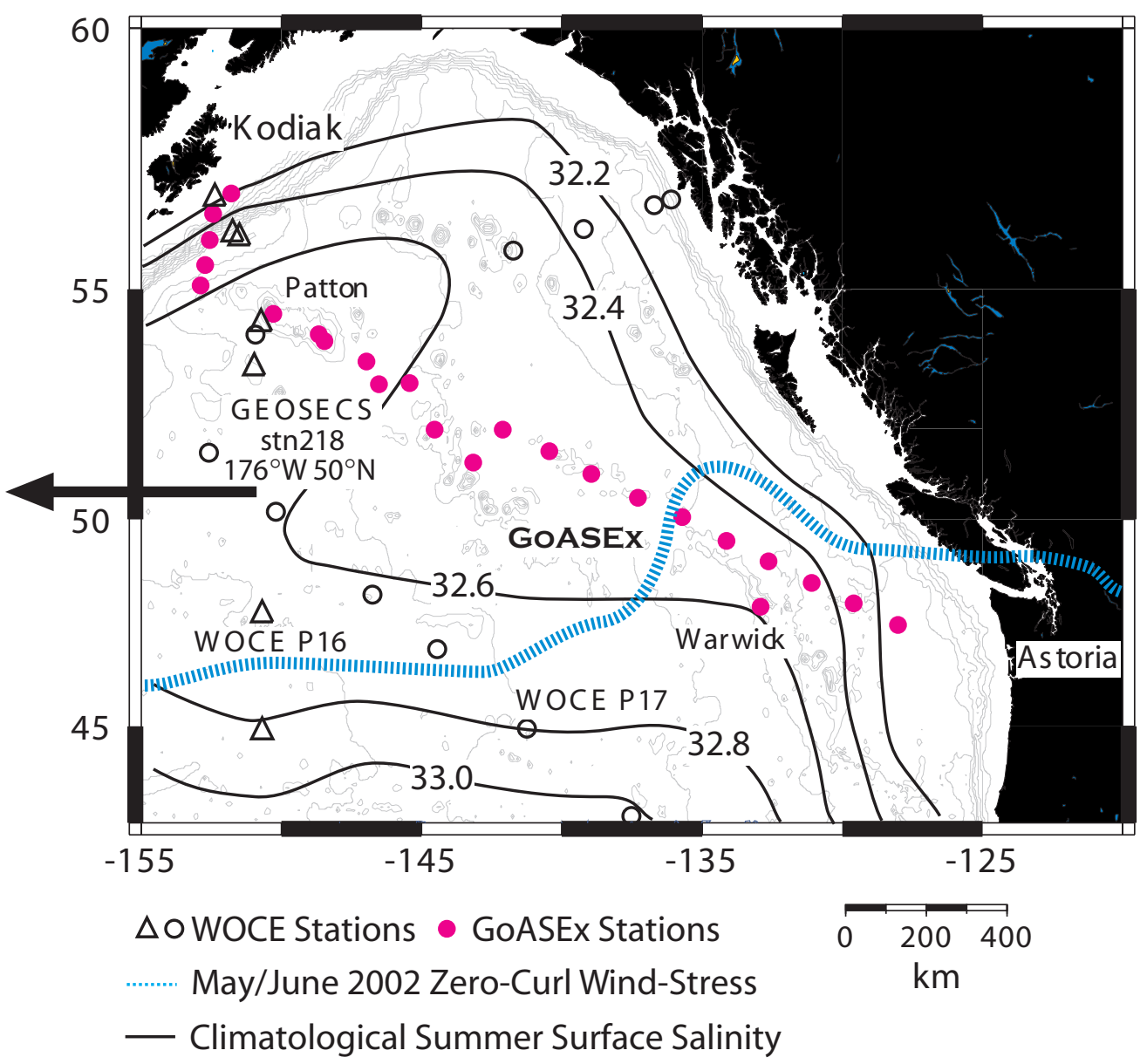

Figure 2 GoASEx underway sample (solid circles) locations relative to WOCE P16 (open triangles) and P17 (open circles) ${ }^{14} \mathrm{C}$-stations. Fine contours are bathymetry. Solid black contours are climatological summer surface salinity (Levitus 1998). Thick striped line is the zero-contour of the curl of the wind-stress based on May/June 2002 winds. GEOSECS station 218 is to the west of this region.

of the primary standard (OX-1) for each pass through a sample group. Counting errors (primary standard and unknown) are propagated through the analysis and are assumed to be Gaussian (cf. Bevington and Robinson 1992). The average of the $n$-measurement cycles of each unknown is then determined, and for the final error, the larger of the counting error or the external error of the $n$ cycles is chosen. CAMS ${ }^{14} \mathrm{C}$ data are based on ${ }^{14} \mathrm{C} /{ }^{13} \mathrm{C}$ atom ratios, not decay counting, to obtain specific ${ }^{14} \mathrm{C}$ activities. The algorithms used (JR Southon, unpublished data) are similar to those developed at Arizona (Donahue et al. 1990). ${ }^{14} \mathrm{C}$ results are reported as absolute fraction modern and equivalent age-corrected $\Delta^{14} \mathrm{C}(\%)$ as defined by Stuiver and Polach (1977) and include a background subtraction and the $\delta^{13} \mathrm{C}$ correction obtained from the stable isotope results. The majority of samples were analyzed in conventional mode to a fractional precision level of $\sim \pm 3.0 \%$ o $(1 \sigma)$.

We took advantage of a subset of the ampoules as a means to test the limits of AMS- ${ }^{14} \mathrm{C}$ analytical precision. For these samples, we made 2 individual $(\sim 60 \mu$ mole $\mathrm{C})$ graphite targets from the single $\mathrm{CO}_{2}$ ampoule. The graphite targets were then analyzed in what is now being termed "ultra-preci- 
sion" mode. Each wheel load is composed of a suite of about 10 aliquots of the primary (OX1) standard, a single set of secondary standards (OX2, ANU, TIRI B wood), the unknown samples and blanks, and is broken into several groups. In general, a group is composed of 10-14 unknowns with intervening and bracketing primary standards. Samples are analyzed in such a fashion that a single group is completely analyzed prior to proceeding onto the next. A group is analyzed repeatedly such that a suite of bracketing primary standards and the secondary standards are analyzed in conjunction with the unknown samples. For "ultra-precision" samples, 10 unknowns compose a group. Additional secondary standards were analyzed amongst, and as, unknowns. During each cycle, an individual target was analyzed for $50,000{ }^{14} \mathrm{C}$ events. Initially, we had intended on cycling all of the ultra-precision targets at least 20 times (i.e. $1 \times 10^{6}{ }^{14} \mathrm{C}$ events), but beam-time considerations precluded this. The last set of ultra-precision samples were only analyzed for $\sim 7.5 \times 10^{5}{ }^{14} \mathrm{C}$ events.

\section{RESULTS}

Fundamental oceanographic and carbon isotope data are tabulated in Tables 1, 2, and 3. Table 1 contains the underway surface data, and Tables 2 and 3 contain the results from the 2 hydrocasts. For the most part, sea surface temperature (SST) and salinity (SSS) are strongly correlated (Figure 3). Temperature decreases from $\sim 13{ }^{\circ} \mathrm{C}$ to $\sim 9^{\circ} \mathrm{C}$ from $47.5^{\circ} \mathrm{N}$ to $54^{\circ} \mathrm{N}$ before rising to $\sim 12^{\circ} \mathrm{C}$ as one crosses into the Alaskan Stream heading in towards Kodiak. Salinity steadily increases over the same latitudinal range from a low of $\sim 32.1$ at $47.5^{\circ} \mathrm{N}$ to a high of $\sim 33$, again at $54^{\circ} \mathrm{N}$. Salinity dramatically decreases as one exits the Alaskan Gyre and heads north towards Kodiak.

\section{Gulf of Alaska Surface Temperature and Salinity}

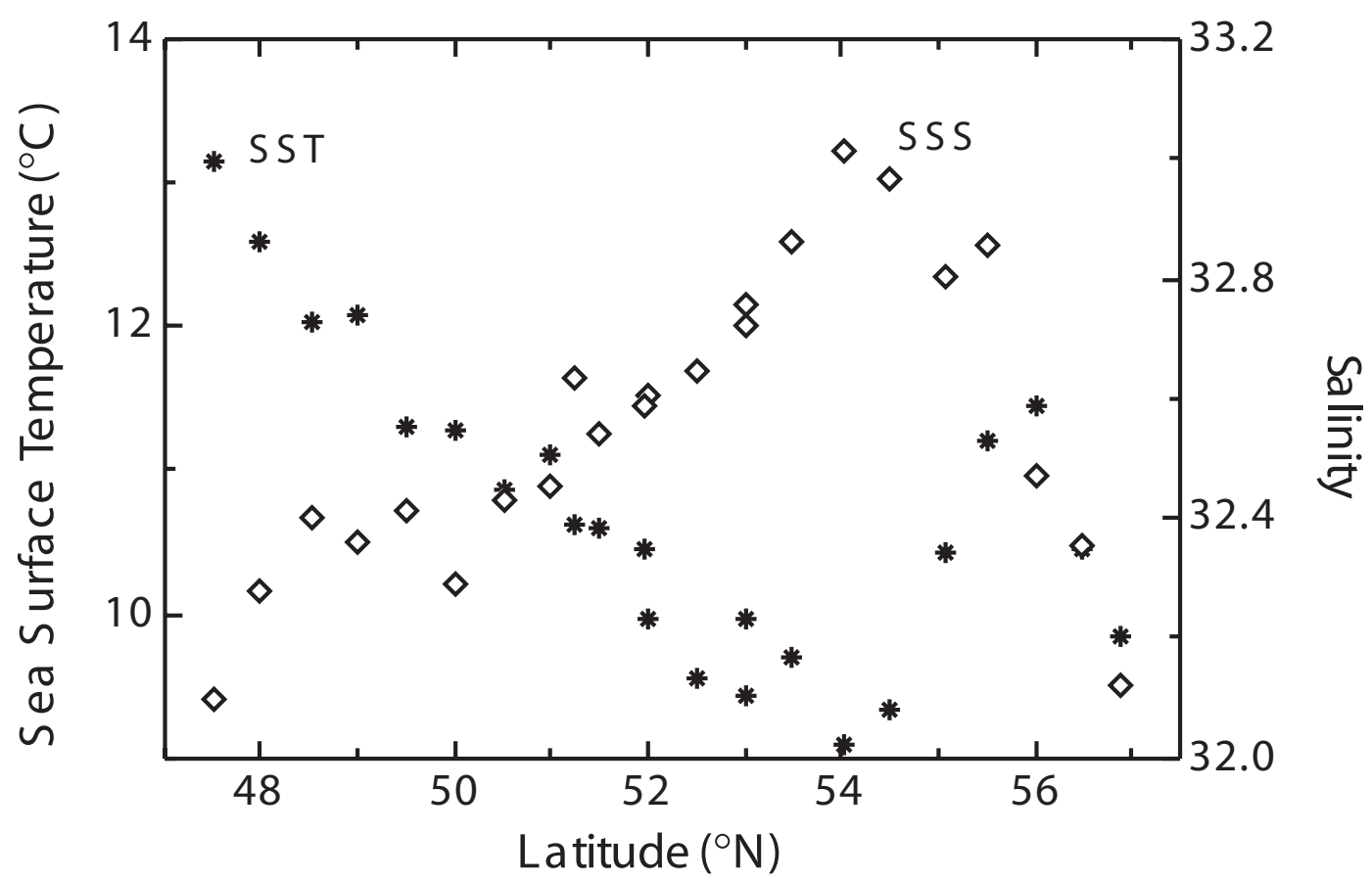

Figure 3 Sea surface temperature (SST, ${ }^{\circ} \mathrm{C}$ ) and surface salinity (SSS, psu) as a function of latitude as observed in June/ July of 2002. 


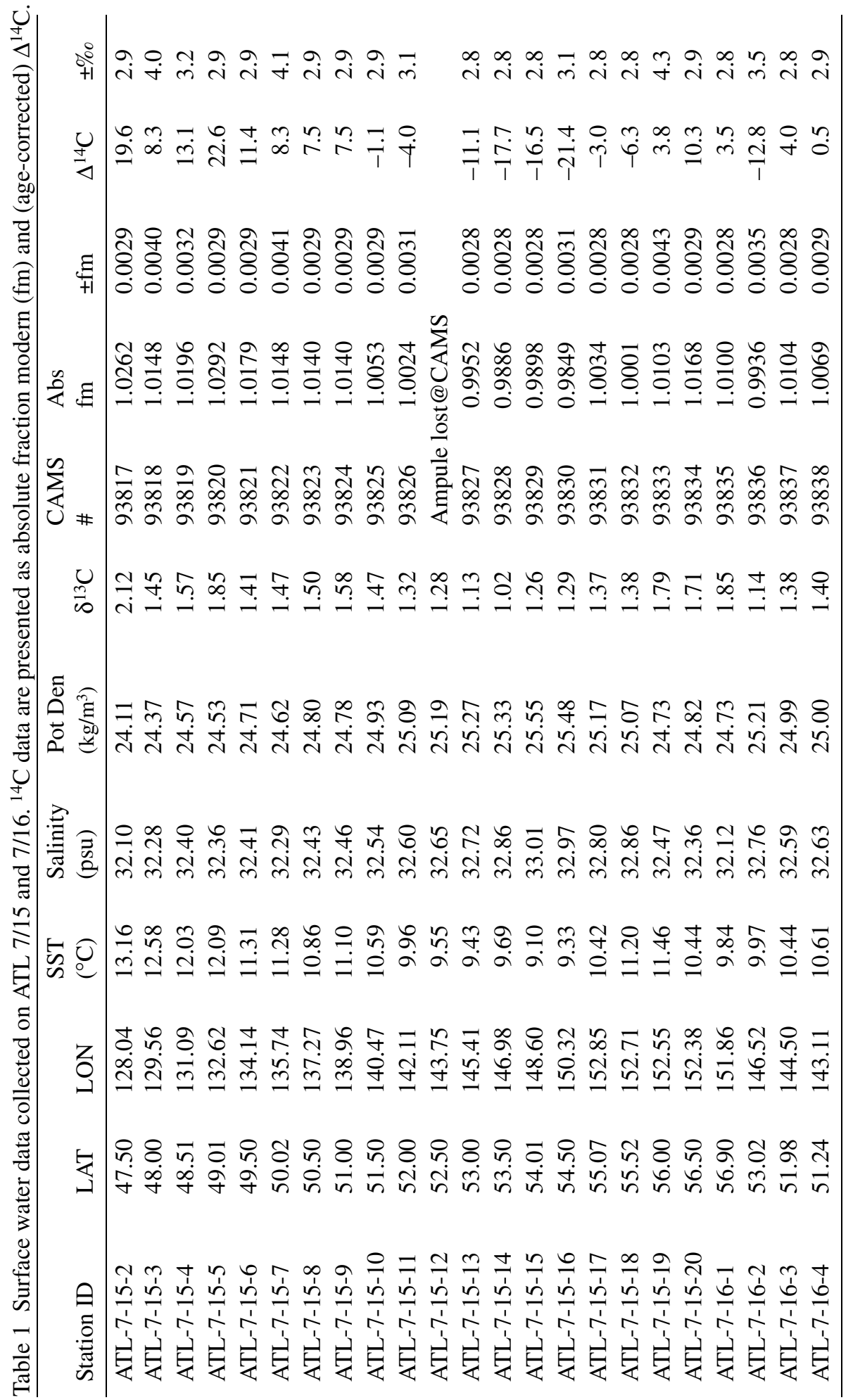




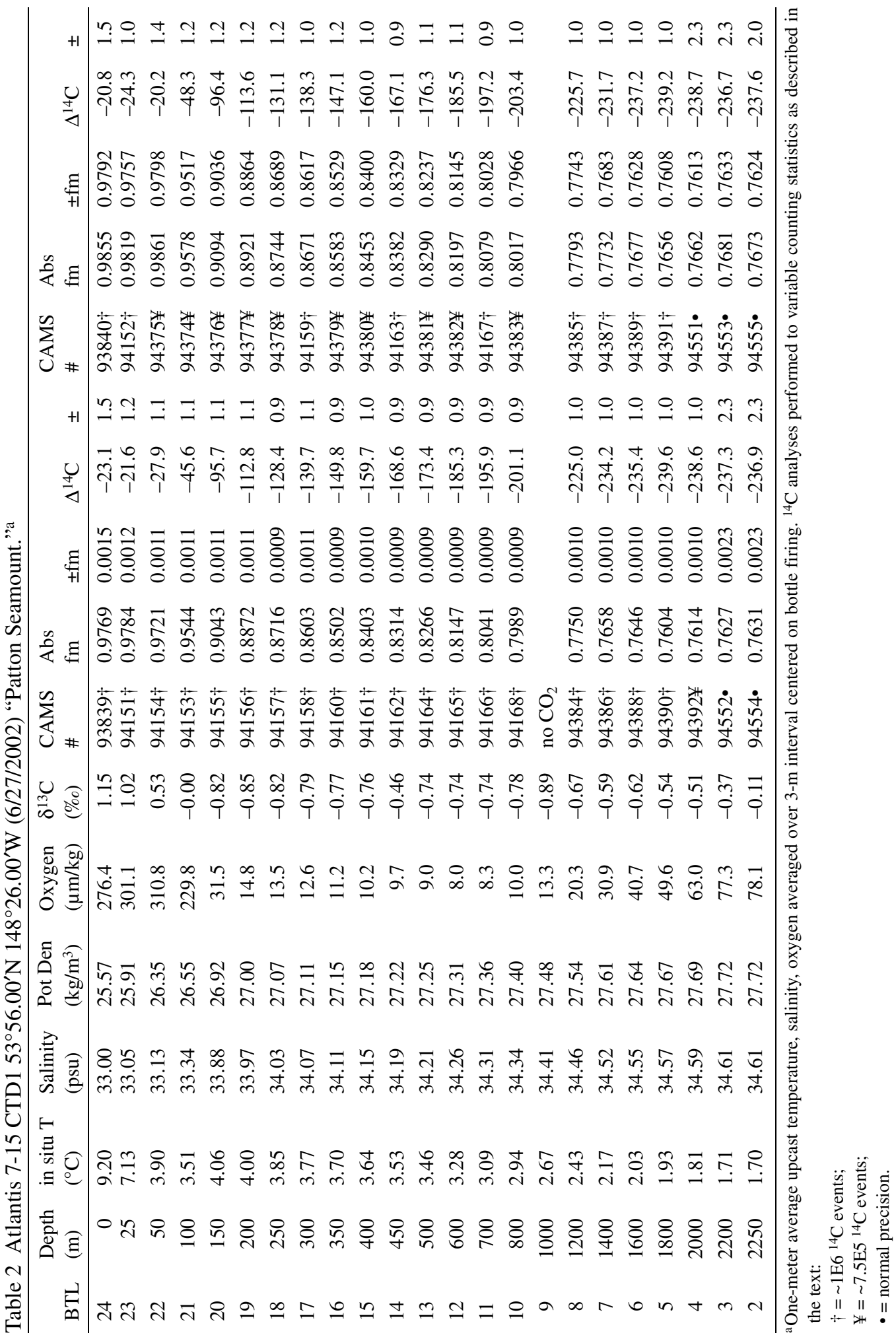




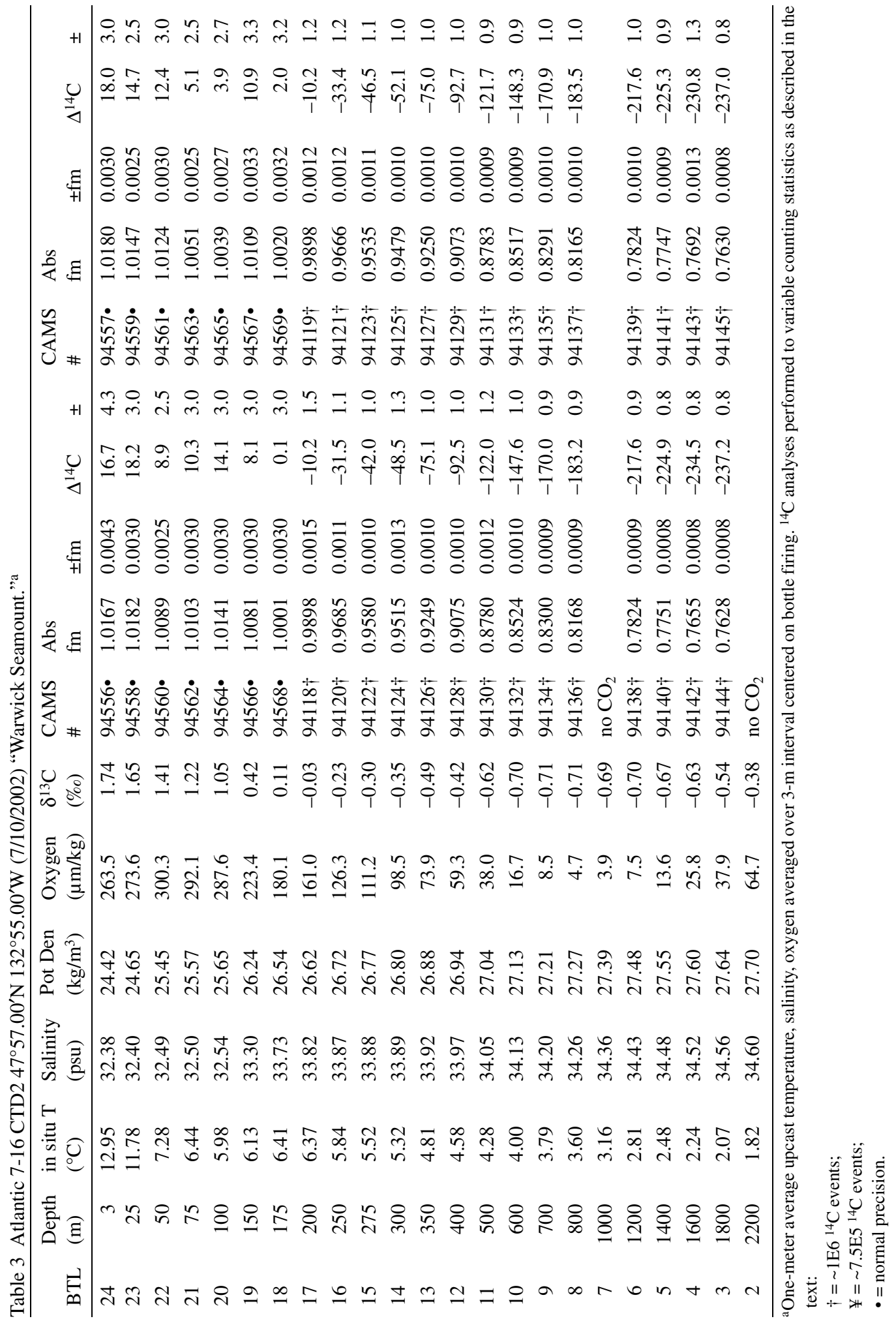


Surface water $\Delta{ }^{14} \mathrm{C}$ values as a function of latitude have a pronounced $V$ shape (Figure 4). The highest values that we observed $(\sim+20 \%)$ were at the southward edge of the Alaskan Gyre $\left(47.5^{\circ} \mathrm{N}\right)$ and the lowest values $\left(\sim-20 \%\right.$ ) at $55^{\circ} \mathrm{N}$. Further north as one crosses the Alaskan Stream, values increase to $\sim+10 \%$. The open gyre values are $20-40 \%$ o lower than those documented in 1991 and 1993 (WOCE; data of Key et al. 1996), although the general latitudinal trend is reproduced.

A.

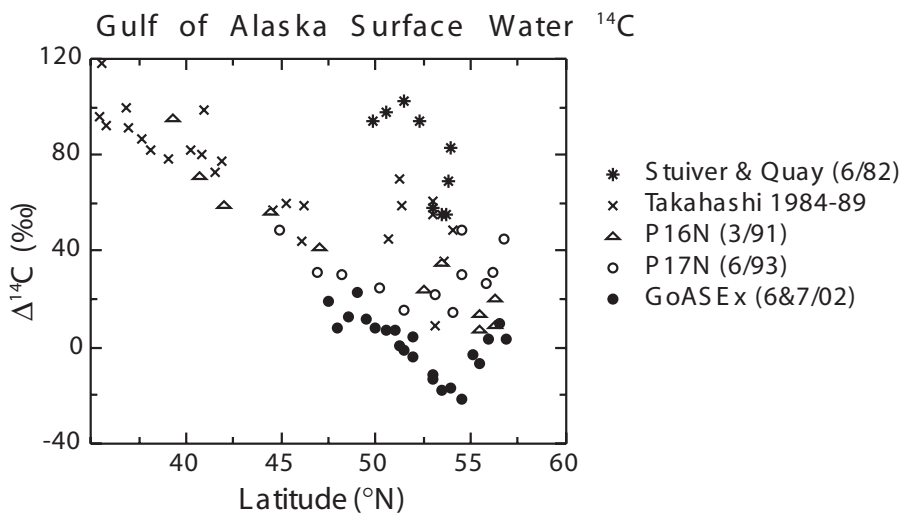

B.

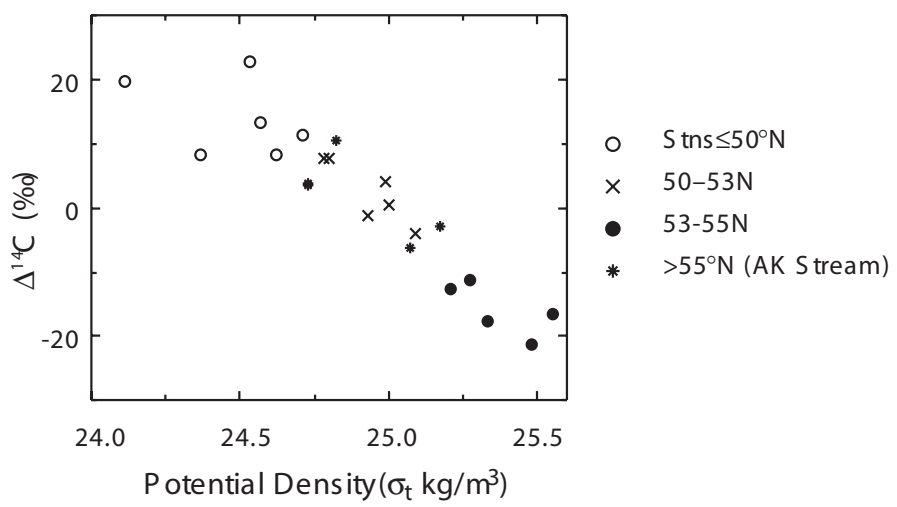

Figure 4 a) Surface $\Delta^{14} \mathrm{C}$ as a function of latitude during the summer of 2002 (solid circles), March of 1991 (P16, open triangles), and June of 1993 (P17, open circles); b) GoASEx surface $\Delta^{14} \mathrm{C}$ as a function of density and latitude (water mass).

Vertical profiles of temperature, salinity, oxygen, and $\Delta^{14} \mathrm{C}$ at Patton (ATL 7-15 ctd 1) and Warwick (ATL 7-16 ctd 2) seamounts (Figure 5) exhibit common features: strong halocline, subsurface temperature maximum, thick oxygen minimum zone, and a subsurface oxygen maximum above the main halocline. As documented in ATL 7-15 ctd 1, temperatures at Patton Seamount decrease from $\sim 9{ }^{\circ} \mathrm{C}$ at the surface to $\sim 3.4{ }^{\circ} \mathrm{C}$ at $\sim 80 \mathrm{~m}$. The main thermocline is at $\sim 27 \mathrm{~m}$. There is a subsurface temperature maximum of $\sim{ }^{\circ} \mathrm{C}$ at $\sim 140 \mathrm{~m}$ near the base of the halocline. Below the subsurface maximum, temperature decreases to $\sim 1.6{ }^{\circ} \mathrm{C}$ at $2200 \mathrm{~m}$. Salinity increases from $\sim 33.00$ at the surface through a mini-halocline at $\sim 25 \mathrm{~m}$, where values become nearly constant at 33.14 between $\sim 50$ and $\sim 80 \mathrm{~m}$. The main halocline is at $110 \mathrm{~m}$ (33.50) and rolls over at $\sim 140 \mathrm{~m}$ (33.84), after which salinity gently increases with depth to 34.62 at $2200 \mathrm{~m}$. Surface water oxygen concentration at Patton is $\sim 276 \mu \mathrm{mole} / \mathrm{kg}$. Oxygen concentration increases with depth through the main thermocline to a sub- 
surface maximum of $\sim 314 \mu \mathrm{m} / \mathrm{kg}$ at $30 \mathrm{~m}$. Oxygen remains high until $\sim 80 \mathrm{~m}$ and then decreases in a 2-step fashion across the main halocline. Oxygen values at Patton are low $(8.2-10.2 \mu \mathrm{m} / \mathrm{kg})$ between $\sim 200 \mathrm{~m}$ and $\sim 800 \mathrm{~m}$ and then increase with depth to $78 \mu \mathrm{m} / \mathrm{kg}$ by $2200 \mathrm{~m}$.
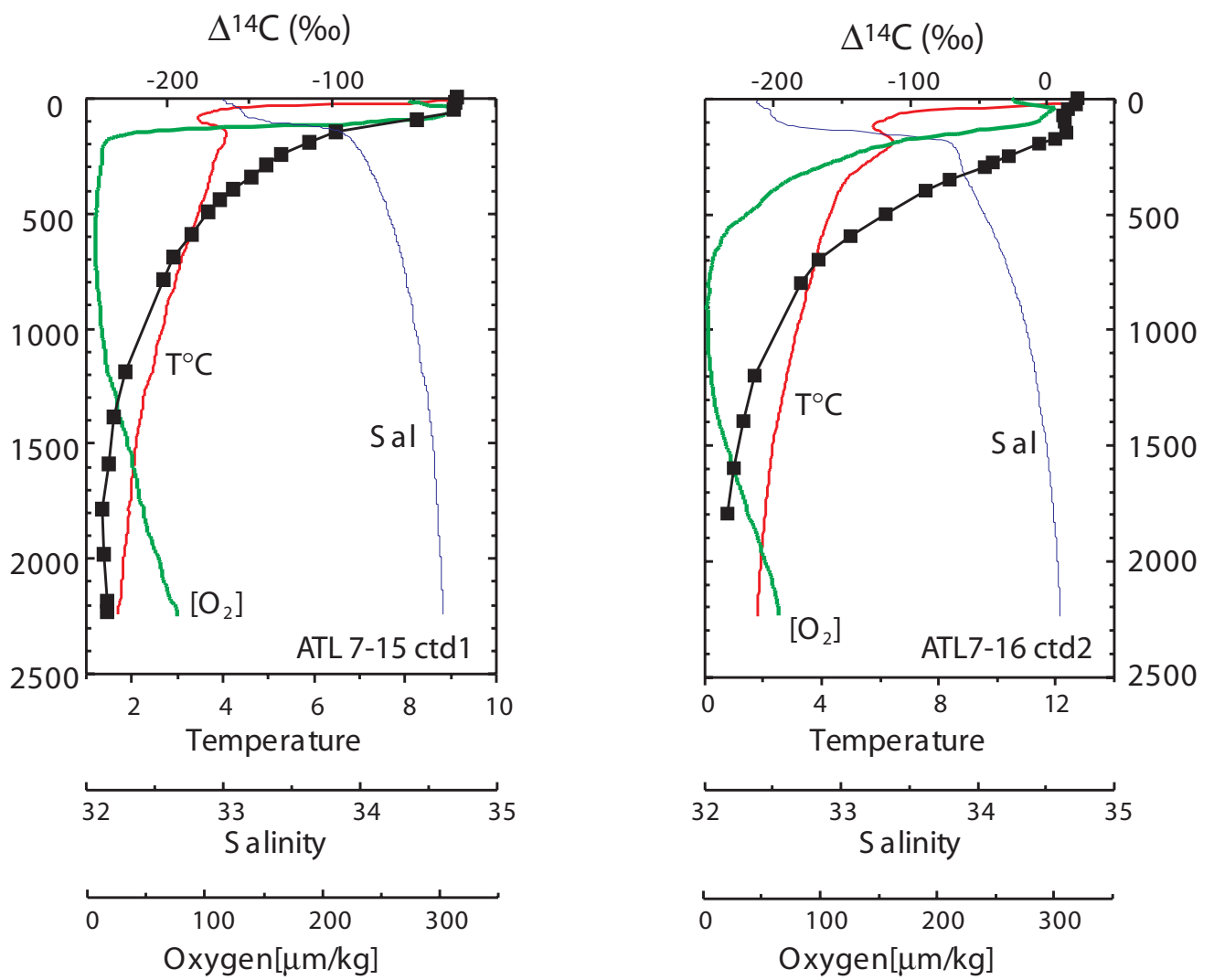

Figure 5 Patton (ATL 7-15 ctd1) and Warwick (ATL7-16 ctd2) hydrographic profiles to 2200 m: temperature (solid line), salinity (thin solid line), oxygen concentration (gray line), and $\Delta^{14} \mathrm{C}$ (connected solid squares). Note the well-mixed $\Delta^{14} \mathrm{C}$ surface layer trapped above the halocline and that the lowest $\Delta^{14} \mathrm{C}$ values do not occur in the oxygen minimum zone.

Temperature at Warwick Seamount as observed in ATL 7-16 ctd2 decreases from $12.9^{\circ} \mathrm{C}$ at the surface through the main thermocline $(\sim 40 \mathrm{~m})$ to $\sim 7.2^{\circ} \mathrm{C}$ at $50 \mathrm{~m}$. Temperature slowly decreases to $\sim 5.8^{\circ} \mathrm{C}$ at $110 \mathrm{~m}$ where a $\sim 20$ - $\mathrm{m}$ thermostad is observed. Temperature increases below the thermostad $(\sim 130 \mathrm{~m})$ to a subsurface maximum of $\sim 6.4{ }^{\circ} \mathrm{C}$ at $\sim 185 \mathrm{~m}$. Except for a slight pause at $\sim 850 \mathrm{~m}$, temperature decreases steadily to $\sim 1.8^{\circ} \mathrm{C}$ at $2200 \mathrm{~m}$. Salinity slowly increases from 32.38 at the surface to 32.65 at the top of the halocline $(120 \mathrm{~m})$. The main halocline is at $140 \mathrm{~m}$ and rolls over by $185 \mathrm{~m}$ (33.79). Salinity gradually increases to 33.91 at $340 \mathrm{~m}$ and then increases in a more regular fashion to 34.60 at $2200 \mathrm{~m}$. Oxygen concentrations increase from $264 \mu$ molar at the surface to a subsurface maximum of $302 \mu \mathrm{mole} / \mathrm{kg}$ at $42 \mathrm{~m}$ and high oxygen concentrations to the halocline. Below the halocline, oxygen concentration rapidly decreases to a 300-m-thick oxygen minimum (2.8-5.5 $\mu \mathrm{m} / \mathrm{kg}$ ) zone between $\sim 800$ and $\sim 1100 \mathrm{~m}$. Oxygen concentration increases to $\sim 64 \mu \mathrm{m} / \mathrm{kg}$ by $2200 \mathrm{~m}$.

In both hydrographic profiles, there is a well-mixed (with respect to $\Delta^{14} \mathrm{C}$ ) surface layer. At Patton Seamount, this layer is mixed to at least $50 \mathrm{~m}$ but less than $100 \mathrm{~m}$ and would be consistent with the 
depth of the main thermocline, but not through the main halocline. At Warwick Seamount, the constant $\Delta{ }^{14} \mathrm{C}$ layer penetrates into the main halocline and extends to $\sim 150 \mathrm{~m}$. Below the surface mixed layer, values decrease as a function of depth. The minimum observed $\Delta^{14} \mathrm{C}$ value at Patton Seamount is $-239 \%$ and $-237 \%$ at Warwick Seamount. The minima are not observed in the oxygen minimum zone but in the water mass below it. Corresponding $\Delta^{14} \mathrm{C}$ in the Patton Seamount bottle samples with the lowest oxygen content are $~-190 \%$, and the one sample at Warwick is $-183 \%$. ${ }^{14} \mathrm{C}$ results on samples from deep interior waters are similar and consistent with existing measurements made during WOCE, GEOSECS, and cruises of opportunity.

The "ultra-precision" replicates were determined over the span of 3 different sample wheels and 2 different AMS runs and include both "within" wheel and between wheel replicates-i.e. a realistic albeit limited test of external variability. As discussed in the Methods section, due to beam-time limitations some of the samples were only analyzed for $7.5 \times 10^{5}{ }^{14} \mathrm{C}$ events, not the full $1 \times 10^{6}$. The average relative error of the 33 pairs of targets is $0.94 \%$ (Figure 6). The majority of the pairs replicate within $1 \sigma, 2$ pairs at $2 \sigma$, and the third will keep us honest.

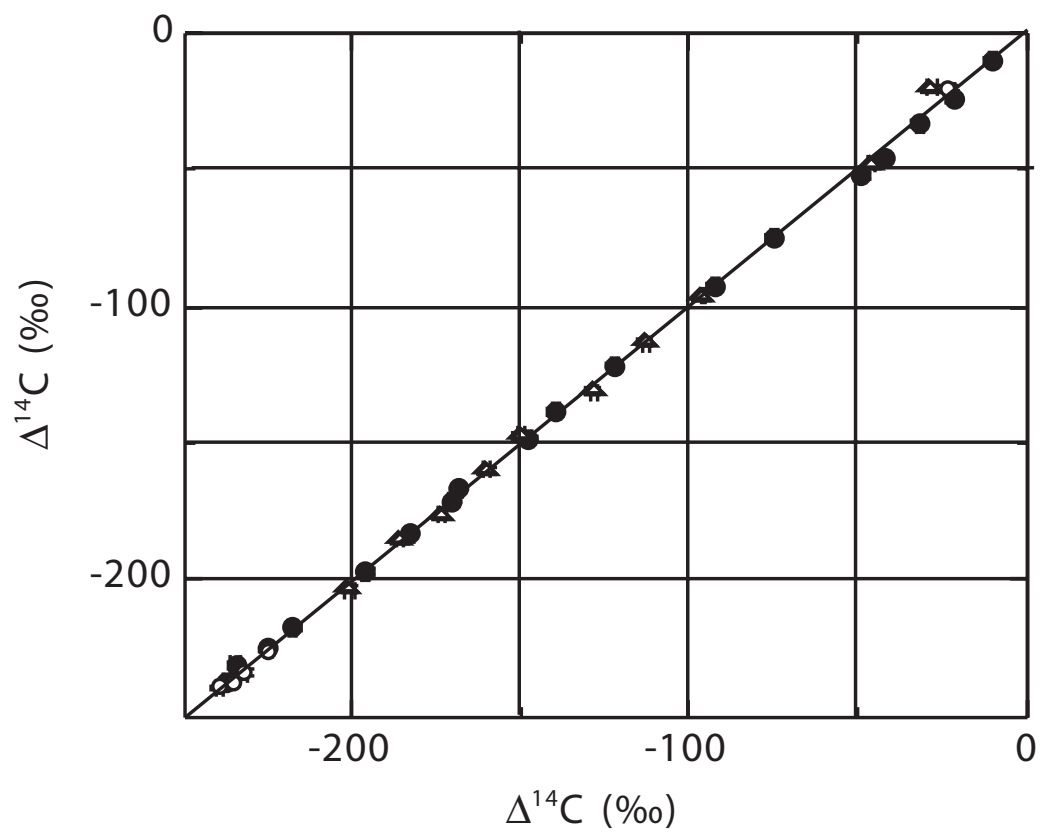

Figure $6 \Delta^{14} \mathrm{C}$ results on $\mathrm{CO}_{2}$ extracted from Gulf of Alaska seawater samples. Single ampoules of $\mathrm{CO}_{2}$ were split to produce 2 independent graphitization targets and pairs were analyzed on the same and/or different sample wheels. The relative or fractional error of the 33 individual pairs scatter with a mean error of $0.94 \%$. The majority of pairs are analytically indistinguishable from each other at $1 \sigma(\mathrm{sd})$.

\section{DISCUSSION}

\section{Evolution of ${ }^{14} \mathrm{C}$ and Ocean Circulation}

Surface $\Delta^{14} \mathrm{C}$ has a somewhat simpler albeit noisier linear relationship to temperature than salinity. Higher $\Delta^{14} \mathrm{C}$ is observed at warmer temperatures, with lower $\Delta^{14} \mathrm{C}$ corresponding with cooler and saltier waters. This results in a near-linear relation between $\Delta^{14} \mathrm{C}$ and potential density (Figure 4). In 
density space, $\Delta^{14} \mathrm{C}$ values of the Alaskan Stream (stations north of $55^{\circ}$ ) are indistinguishable from stations in the middle of the gyre $\left(50-53^{\circ} \mathrm{N}\right)$. These $\Delta^{14} \mathrm{C}$ values are intermediate between the low values observed towards $55^{\circ} \mathrm{N}$ and the high $\Delta^{14} \mathrm{C}$ at the warm, fresh end to the south. This gives the distinct impression of a simple 2-end-member mixing model between a low- ${ }^{14} \mathrm{C}$ end-member at $\sim 25.5 \mathrm{~kg} \mathrm{cc}^{-3}$ and a high- ${ }^{14} \mathrm{C}$ end-member $<24.5 \mathrm{~kg} \mathrm{cc}^{-3}$. We can take advantage of this relationship to explore mixing processes in the Gulf of Alaska.

If we make the logical assumption that the Alaskan Current is sourced from water at the southern gyre boundary, our limited data indicates that there is an addition of $10{ }^{-14} \mathrm{C}$ water through vertical entrainment or from freshwater coastal run-off. Depending upon the source of the ${ }^{10 w}-{ }^{14} \mathrm{C}$ water requires density modification to fit the simple 2-end-member mixing model. In the case of vertical entrainment, this could be accomplished through radiative heating and freshening to decrease the salinity of subsurface saltier waters. In the case of coastal (freshwater) run-off, evaporation would be required to increase the salt content. Freshwater run-off is likely to have a $\Delta^{14} \mathrm{C}$ signature similar to the atmosphere, which is higher than Gulf of Alaska surface waters and therefore would be a source of higher $\Delta^{14} \mathrm{C}$. We thus infer that vertical mixing/entrainment is an important dynamic process that mixes low- ${ }^{14} \mathrm{C}$ water into the surface mixed layer of the central gyre. Our observations also imply that there is little modification of the ${ }^{14} \mathrm{C}$ content in the Alaskan Current/Stream, at least during late spring and into early summer.

Near Patton and Warwick seamounts, the salinity and density that defines NPIW occurs at the base of the halocline: $~ 150-200 \mathrm{~m}$ at Patton (ATL 7-15 ctd1) and 185-350 m at Warwick (ATL 7-16 ctd2). The thick $\sim 33.9$-psu water mass and salinity inflection observed in the vertical profile at Warwick leaves no doubt as to the occurrence of NPIW, whereas at Patton the layer is rather thin. $\Delta^{14} \mathrm{C}$ values of thermocline and NPIW waters at Warwick are higher than similar density (salinity) waters to the north as observed at Patton. This observation could be interpreted as more bomb ${ }^{14} \mathrm{C}$ in the ventilated waters around Warwick Seamount compared to subhalocline central gyre waters to the north. An equally valid statement would be that the central Alaskan Gyre waters has diluted its "bomb- ${ }^{14} \mathrm{C}$ " signature to a greater extent with $l o w-{ }^{14} \mathrm{C}$ water. At depths deeper than NPIW, the waters sampled by the 2 hydrocasts are indistinguishable in density (salinity) $\Delta^{14} \mathrm{C}$ space. Subtropical surface waters are the likely source of the higher ${ }^{14} \mathrm{C}$ signature observed at Warwick relative to Patton. Subtropical (higher- ${ }^{14} \mathrm{C}$ ) waters would be entrained into the southern edges of the Alaskan Gyre through interaction with the North Pacific Current.

Relative to the (spatially) equivalent WOCE P16 (58) and P17 (127) stations, waters in the Gulf of Alaska in 2002 have lower $\Delta^{14} \mathrm{C}$ for a given potential density $\left(\sigma_{t}\right)$ than those in the early 1990s (Figure 7). Indeed, none of the WOCE $\Delta^{14} \mathrm{C}$ profiles approach the consistently low values observed at Patton Seamount (ATL 7-15 ctd1) for densities less than $\sim 26.7 \sigma_{\mathrm{t}}$ and for the most part the same can be said for the transition or gyre boundary at Warwick (ATL7-16 ctd2). Comparison of our $\Delta^{14} \mathrm{C}$ data to GEOSECS indicates erosion of the transient bomb ${ }^{14} \mathrm{C}$ signature to a density of $\sim 26.8$ or a depth of $\sim 160 \mathrm{~m}$ at station $218\left(50.43^{\circ} \mathrm{N}, 176.58^{\circ} \mathrm{W}\right)$. In June 1982 , Gulf of Alaska surface water $\Delta^{14} \mathrm{C}$ values approached $100 \%$ at a latitude of $51.5^{\circ} \mathrm{N}$ (Stuiver and Quay 1982). By the late 1980s, surface water $\Delta^{14} \mathrm{C}$ had decreased to a maximum of $\sim 70 \%$, with the highest values again around $50^{\circ} \mathrm{N}$ (Takahashi et al. 1991). Values observed in the early 1990s as part of WOCE continue the trend towards lower $\Delta^{14} \mathrm{C}$. The surface data document a steady erosion of the bomb- ${ }^{14} \mathrm{C}$ transient from the 1970 s to the present.

In the north Pacific, pre-bomb $\Delta^{14} \mathrm{C}$ surface water values are thought to be lower in the western subpolar North Pacific where low- ${ }^{14} \mathrm{C}$ water is entrained into the surface mixed layer through vigorous 
Gulf of Alaska $\Delta^{14} \mathrm{C}$ and Potential Density

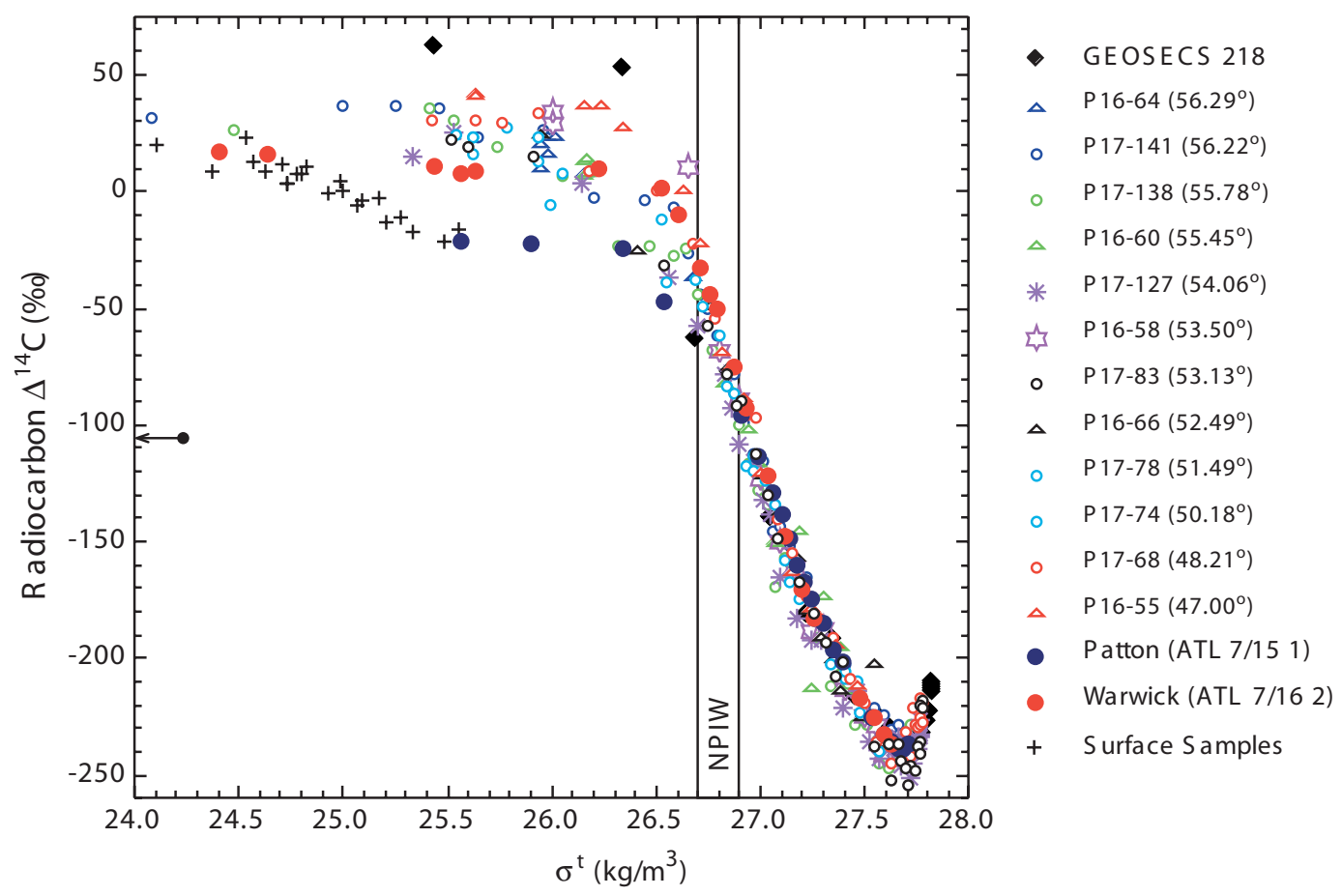

Figure 7 Temporal evolution of $\Delta{ }^{14} \mathrm{C}$ in the Gulf of Alaska as a function of potential density. Snapshots include: 1991 (P16, open triangles); 1993 (P17, open circles); and 2002 (GoASEx, solid circles and for surface samples crosses). P17-127 (asterisk) and P16-58 (star) are the two WOCE stations closest to that of Patton ATL07/15-ctd1. For reference, we also plot GEOSECS station 218 (solid diamond: $176.58^{\circ} \mathrm{W}, 50.43^{\circ} \mathrm{N}$ ) taken in the fall of 1973 . Surface pre-bomb value at Warwick as reconstructed from biologic archives (Roark et al. 2005) is demarked by the solid arrow.

vertical mixing and upwelling (cf. Guilderson et al. 2000). $\Delta^{14} \mathrm{C}$ values in the eastern subpolar North Pacific are higher than those in the west, likely due in part to entrainment of higher- ${ }^{14} \mathrm{C}$ subtropical water from the North Pacific Current. Transport of western North Pacific waters would be accommodated in the North Pacific Current. Pre-bomb surface values over Warwick Seamount are inferred to be $\sim-105 \%$ o (Roark et al. 2005), but as of yet we do not know what the values should be in the Alaskan Gyre itself. Our observation of decreasing $\Delta^{14} \mathrm{C}$ surface values through the gyre in addition to lower- $\Delta^{14} \mathrm{C}$ in subthermocline water (NPIW) in the north versus the south implies a local source of low- ${ }^{14} \mathrm{C}$ water. Chlorofluorocarbon ages indicate a residence time in the Alaskan Gyre of only a few years (Aydin et al. 1998). This precludes our observation being the result of in situ aging. The likely mechanism is entrainment of low- ${ }^{14} \mathrm{C}$ water and vertical exchange. Based on our data alone, we cannot discount replenishment of surface and subthermocline waters with recently upwelled low- ${ }^{14} \mathrm{C}$ water from the NW Pacific. It is possible that both physical mechanisms have contributed to the erosion of the bomb- ${ }^{14} \mathrm{C}$ transient in the Gulf of Alaska.

The observation that the lowest $\Delta{ }^{14} \mathrm{C}$, and hence ${ }^{14} \mathrm{C}$ age, is not coincident with lowest oxygen concentrations indicates a decoupling between oxygen concentration (or apparent oxygen utilization) and ventilation age. This would be caused by high oxygen consumption during remineralization of organic matter along the margin of northern North America and within the water column under areas of high productivity. 


\section{"Ultra-Precision" ${ }^{14} \mathrm{C}$ Analyses}

The average fractional error of the 33 pairs of carefully "split" $\mathrm{CO}_{2}$ and individually graphitized targets is $0.94 \%$. To the best of our knowledge, these are the first $~ 1 \%$ o AMS results on real-world samples. These results indicate that with high negative ion sputter efficiency and complete beam transport, it is possible to achieve results comparable to the best liquid scintillation laboratories. In this experiment, we did not see the deleterious and potentially limiting effects described by Nadeau et al. (1987, 1990). We believe that this observation is the result of individual AMS-system and ionsource peculiarities. The CAMS spectrometer system was designed with performance and capabilities not available in commercially available AMS systems or similar systems at many nuclear physics laboratories. All high-energy magnets have $5-\mathrm{cm}$ apertures, and all quadrapole lenses in the beam-line have 10-cm apertures. This results in better optics with complete transmission and no fractionation (Davis et al. 1990, 1992). Unlike many other cesium sputter sources, the CAMS system does not seem to introduce appreciable time-dependent fractionation during the course of analyzing individual targets or at variable ion currents (Southon et al. 1991). Due to the design of the low-energy injection system, no beam is lost even at high source emittance. All this being said, the true test of this type of measurements is not as a "one-off" but long-term reproducibility with precision and accuracy.

\section{CONCLUSIONS}

${ }^{14} \mathrm{C}$ measurements on total dissolved inorganic carbon on water samples from the Gulf of Alaska obtained in 2002 have been compared with similar data from the 1990s (WOCE), the 1970s (GEOSECS), and surface water samples of opportunity taken in the 1980s. The open gyre surface water values are 20-40\%o lower than those documented in 1991 and 1993 (WOCE), continuing the trend towards lower $\Delta^{14} \mathrm{C}$ values since GEOSECS. Within the admittedly limited spatial sampling, erosion of the bomb- ${ }^{14} \mathrm{C}$ transient appears from the surface to densities approaching $26.8 \sigma_{\mathrm{t}}$. In addition to lateral (isopycnal) replenishment with waters from the western Pacific via the general shallow circulation, our data imply a local source of $l o w-{ }^{14} \mathrm{C}$ water. Vertical mixing and entrainment of water below $26.8 \sigma_{\mathrm{t}}$ is the preferred source of the low- ${ }^{14} \mathrm{C}$ water. This interpretation would be consistent with other tracer data (e.g. Aydin et al. 1998).

In a proof of principle study, we took advantage of a subset of the samples to analyze to a level approaching $1 \%$. Individually graphitized splits of the same $\mathrm{CO}_{2}$ ampoules were analyzed on the same and different wheels. The vast majority replicated to $1 \% o$ at $1 \sigma$ over a range of values from $\sim-240$ to $\sim 0 \%$. The cumulative fractional error of the 33 "pairs" was $0.94 \%$. The results of this experiment indicate that AMS has the potential to equal the precision and accuracy of high-precision liquid scintillation counting laboratories.

\section{ACKNOWLEDGMENTS}

This research was funded by the NOAA Office of Ocean Exploration (NA16RP2637) to TG. We thank the captain and crew of the R/V Atlantis and all members of the GoASEx science party. Sample preparation and assistance at UW by J Stutsman. This manuscript benefited from discussions with T Brown, R Key, T Shirley, and the comments of an anonymous reviewer. ${ }^{14} \mathrm{C}$ analyses were performed under the auspices of the U.S. Department of Energy by the University of California Lawrence Livermore National Laboratory (contract W-7405-Eng-48). 


\section{REFERENCES}

Aydin M, Top Z, Fine RA, Olson DB. 1998. Modification of the intermediate waters: I. the northeastern subpolar Pacific. Journal of Geophysical Research 103: 30,923-40.

Bevington PR, Robinson DK. 1992. Data Reduction and Error Analysis for the Physical Sciences. 2nd edition. Boston: McGraw-Hill. 328 p.

Davis JC, Proctor ID, Southon JR, Caffee MW, Heikkinen DW, Roberts ML, Moore TL, Turteltaub KW, Nelson DE, Loyd DH, Vogel JS. 1990. LLNL/UC AMS facility and research program. Nuclear Instrument and Methods in Physics Research B 52:269-72.

Davis JC, Proctor ID, Heikkinen DW, Hornady RS, Roberts ML, Southon JR, Bench GS, Pontau AE, Morse DH. 1992. Ion beam and isotopic analysis tools at Livermore [report presented at International Conference on Applications of Nuclear Techniques]. Mykonos, Greece, 6-13 June 1992.

Dickson AG, Goyet C. 1994. Handbook of methods for the analysis of the various parameters of the carbon dioxide system in seawater. Version 2, ORNL/CDIAC74.

Donahue DJ, Linick TW, Jull AJT. 1990. Isotope-ratio and background corrections for accelerator mass spectrometry radiocarbon measurements. Radiocarbon 32(1):135-42.

Guilderson TP, Caldeira K, Duffy PB. 2000. Radiocarbon as a diagnostic tracer in ocean and carbon cycle modeling. Global Biogeochemical Cycles 14:887902.

Key RM, Quay PD, Jones GA, McNichol AP, von Reden KF, Schneider RJ. 1996. WOCE AMS radiocarbon I: Pacific Ocean results (P6, P16 and P17). Radiocarbon 38(3):425-518.

Monterey GI, Levitus S. 1997. Seasonal Variability of Mixed Layer Depth for the World Ocean. NOAA NESDIS Atlas 14. Washington, D.C.: U.S. Government Printing Office.

Nadeau MJ, Litherland AE. 1990. Electric dissociation of negative ions. Nuclear Instruments and Methods in Physics Research B 52:387-90.

Nadeau MJ, Kieser WE, Buekens RP, Litherland AE. 1987. Quantum mechanical effects on sputter source isotope fractionation. Nuclear Instruments and Methods in Physics Research B 29:83-6.

Reid J, Arthur RS. 1975. Interpretation of maps of geopotential anomaly for deep Pacific Ocean. Journal of Marine Research 33(suppl):37-52.

Roark EB, Guilderson TP, Flood-Page S, Dunbar RB, Ingram BL, Fallon SJ, McCulloch M. 2005. Radiocarbon-based ages and growth rates of bamboo corals from the Gulf of Alaska. Geophysical Research Letters (32): L04606, doi:10.1029/2004GL021919.

Southon JR, Vogel JS, Trumbore SE, Davis JC, Roberts ML, Caffee MW, Finkel RC, Proctor ID, Heikkinen DW, Berno AJ, Hornady RS. 1991. Progress in AMS measurements at the LLNL spectrometer. Radiocar- bon 34(3):473-7.

Stuiver M, Polach H. 1977. Discussion: reporting of ${ }^{14} \mathrm{C}$ data. Radiocarbon 19(3):355-63.

Stuiver M, Quay PD. 1982. Data published in: Reeburgh WS, Kipphut GW. 1986. Chemical distributions and signals in the Gulf of Alaska, its coastal margins and estuaries. NOAA/USDI Alaska OCS study \#MMS 860095, Minerals Management Service, U.S. Department of the Interior.

Sverdrup HU, Johnson MW, Fleming RH. 1942. The Oceans. Englewood Cliffs, New Jersey: PrenticeHall. $1087 \mathrm{p}$.

Takahashi T, Goddard J, Sutherland SC, Mathieu G, Chipman DW. 1991. Assessment of carbon dioxide sink/source in the North Pacific Ocean: seasonal and geographic variability, 1984-1989. Final report for DOE contract 19X-SC428C, submitted to CDIAC, Environmental Sciences Div., Oak Ridge National Lab, Oak Ridge, Tennessee 37939, USA.

Takahashi T, Feely RA, Weiss RF, Wanninkhof R, Chipman DW, Sutherland SC, Takahashi TT. 1997. Global air-sea flux of $\mathrm{CO}_{2}$ : an estimate based on measurements of sea-air $\mathrm{pCO}_{2}$ difference. Proceedings of the National Academy of Sciences 94:8292-9.

Talley LD. 1993. Distribution and formation of North Pacific Intermediate Water. Journal of Physical Oceanography 23:517-37.

Talley LD. 1991. An Okhotsk Sea water anomaly: implications for ventilation in the North Pacific. Deep-Sea Research 38(suppl):S171-S190.

Talley LD, Joyce TM, deSzoeke RA. 1991. Transpacific sections at $47^{\circ} \mathrm{N}$ and $152^{\circ} \mathrm{W}$ : distribution of properties. Deep-Sea Research 38(suppl):S63-S82.

Tsunogai S, Watanabe S, Honda M, Aramaki T. 1995. North Pacific Intermediate Water studied chiefly with radiocarbon. Journal of Oceanography 51:519-36.

Van Scoy KA, Fine RA, Östlund HG. 1991a. Two decades of mixing tritium into the North Pacific Ocean. Deep-Sea Research 38(suppl):S191-S219.

Van Scoy KA, Olson DB, Fine RA. 1991b. Ventilation of North Pacific Intermediate Waters: the role of the Alaskan Gyre. Journal of Geophysical Research 96: $16,801-10$.

Vogel JS, Southon JR, Nelson DE. 1987. Catalyst and binder effects in the use of filamentous graphite for AMS. Nuclear Instruments and Methods in Physics Research B 29:50-6.

Warner MJ, Bullister JL, Wisegarver DP, Gammon RH, Weiss RF. 1996. Basin-wide distribution of chloroflurocarbons CFC-11 and CFC-12 in the North Pacific: 1985-1989. Journal of Geophysical Research 101: 20,525-42.

Watanabe YW, Harada K, Ishikawa K. 1994. Chlorofluorocarbons in the central North Pacific and southward spreading time of North Pacific Intermediate Water. Journal of Geophysical Research 99:25,195-213. 